\title{
Subnuclear segregation of genes and core promoter factors in myogenesis
}

\author{
Jie Yao, ${ }^{1,2}$ Richard D. Fetter, ${ }^{1}$ Ping Hu, ${ }^{2}$ Eric Betzig, ${ }^{1}$ and Robert Tjian ${ }^{1,2,3}$ \\ ${ }^{1}$ Janelia Farm Research Campus, The Single Cell Biochemistry Consortium, Howard Hughes Medical Institute, Ashburn, \\ Virginia 20147, USA; ${ }^{2}$ Department of Molecular and Cell Biology, Li Kashing Center For Biomedical and Health Sciences, CIRM \\ Center of Excellence, University of California at Berkeley, Berkeley, California 94720, USA
}

\begin{abstract}
Recent findings implicate alternate core promoter recognition complexes in regulating cellular differentiation. Here we report a spatial segregation of the alternative core factor TAF3, but not canonical TFIID subunits, away from the nuclear periphery, where the key myogenic gene $M y o D$ is preferentially localized in myoblasts. This segregation is correlated with the differential occupancy of TAF3 versus TFIID at the MyoD promoter. Loss of this segregation by modulating either the intranuclear location of the MyoD gene or TAF3 protein leads to altered TAF3 occupancy at the $M y o D$ promoter. Intriguingly, in differentiated myotubes, the $M y o D$ gene is repositioned to the nuclear interior, where TAF3 resides. The specific high-affinity recognition of H3K4Me3 by the TAF3 PHD (plant homeodomain) finger appears to be required for the sequestration of TAF3 to the nuclear interior. We suggest that intranuclear sequestration of core transcription components and their target genes provides an additional mechanism for promoter selectivity during differentiation.
\end{abstract}

[Keywords: transcription; nucleus; MyoD; core promoter factors; superresolution microscopy]

Supplemental material is available for this article.

Received December 12, 2010; revised version accepted January 24, 2011.

The regulation of gene transcription plays a seminal role in the development and differentiation of cell types in multicellular organisms. Significant progress has been made in the identification of transcription factors, and genome-wide mapping of their cognate binding sites has accelerated with the development of massively parallel DNA sequencing capabilities (Farnham 2009). Despite this rapid progress in dissecting the biochemistry of transcription, the question of how these gene regulatory factors find their target promoters in the cell nucleus remains poorly understood. Genomic DNA in eukaryotic cells is compacted by histone proteins to form chromatin-highly folded and condensed protein/DNA structures inside the nucleus (Cremer and Cremer 2001; Spector 2003). Live-cell imaging analysis suggests that many transcription factors rapidly diffuse across the nucleus and transiently bind to their target genes (Darzacq et al. 2009; Hager et al. 2009). Importantly, it has been recognized that genes are nonrandomly distributed in the nucleus and with respect to chromatin territories (Misteli 2007; Kumaran et al. 2008; Sinclair et al. 2010), and that gene activation and cellular differentiation may be accompa-

${ }^{3}$ Corresponding author.

E-MAIL jmlim@berkeley.edu; FAX (510) 643-9547.

Article published online ahead of print. Article and publication date are online at http://www.genesdev.org/cgi/doi/10.1101/gad.2021411. Freely available online through the Genes \& Development Open Access option. nied by gene repositioning (Moen et al. 2004; Chuang et al. 2006; Meister et al. 2010). Although the position of a gene in the nucleus does not obligatorily determine its activity (Yao et al. 2007; Kumaran et al. 2008), transcription factors must be able to navigate the cell nucleus and access target genes in order to activate transcription. Thus, an important but challenging question that has largely escaped analysis is whether access and targeting of transcription factors to specific nuclear subcompartments can influence and regulate transcription output. From a technical standpoint, although live-cell imaging provides some measurement of mobility and kinetics of populations of transcription factor molecules in the nucleus, individual transcription factor molecules are not readily visible within the context of nuclear architecture using conventional light microscopy. Recent advances in fluorescence microscopy with single-molecule resolution provide us an opportunity to revisit this problem of transcription factor accessibility and selective utilization at target gene promoters.

Another challenge to accurate subnuclear positioning of regulatory factors is the relative paucity of spatial landmarks within the nucleus. One readily recognizable positional element is the nuclear periphery, demarcated by structures at the inner surface of the nuclear envelope (Akhtar and Gasser 2007; Lusk et al. 2007). Interactions of chromatin domains with the nuclear lamina (NL) have been identified during embryonic stem cell differentiation 
(Peric-Hupkes et al. 2010). In yeast, components of the nuclear periphery have been implicated in both repression and activation of gene transcription (Andrulis et al. 1998; Schmid et al. 2006). In mammalian cells, experiments that tether reporter genes to the nuclear periphery have resulted in differential expression of some, but not all, reporters, as well as adjacent endogenous genes (Finlan et al. 2008; Kumaran and Spector 2008; Reddy et al. 2008). We speculate that identifying transcription factors that exhibit differential access to the nuclear periphery may be informative in exploring the potential roles of nuclear organizations of genes and proteins as a mechanism of gene control.

Our recent analysis of skeletal myogenesis suggests that alternate core promoter recognition factors may play a hitherto unappreciated role in regulating cell typespecific transcription (Deato and Tjian 2007; Deato et al. 2008; D'Alessio et al. 2009; Goodrich and Tjian 2010). During muscle formation, the $M y o D$ gene is expressed in both myoblasts and later in differentiated myotubes and acts as a key regulatory factor driving myogenic differentiation (Tapscott et al. 1988). In contrast, the Myogenin gene is turned on only after myocytes exit the cell cycle and begin to fuse, thus activating genes at later stages of differentiation (Edmondson and Olson 1989). Another recently uncovered transcriptional event associated with skeletal myogenesis was the unexpected loss of the prototypic core promoter recognition complex TFIID (Deato and Tjian 2007). It had been well established that, in rapidly growing cells, the multisubunit core transcription complex TFIID is essential for promoter recognition and potentiating activated transcription from yeast to humans (Naar et al. 2001). TAF3 is a substoichiometric TFIID subunit first identified in Drosophila (Gangloff et al. 2001), and later shown to interact with the histone mark H3K4Me3 (Vermeulen et al. 2007). Remarkably, during myoblast-to-myotube differentiation of mouse $\mathrm{C} 2 \mathrm{C} 12$ cell culture and during muscle development in vivo, TFIID is largely eliminated, and, instead, TAF3 can be detected associated with the core promoter of the late-expressing Myogenin gene (Deato and Tjian 2007). Curiously, in myoblasts, TFIID and TAF3 are both present in the same nucleus, but how myogenic genes differentially use TFIID versus TAF3 in myoblasts posed an intriguing conundrum.

Here we tracked two key myogenic genes-MyoD and Myogenin-and alternate core promoter recognition factors by fluorescence in situ hybridization (FISH), immunofluorescence staining, and dual-color photoactivation localization microscopy (PALM). By employing "superresolution" PALM-based cell imaging approaches, we more precisely localized individual transcription factor molecules within distinct nuclear regions. We found that, in myoblasts, canonical TFIID subunits are present at the nuclear periphery, where the $M y o D$ gene preferentially resides, while TAF3 is largely segregated from the nuclear periphery; this differential subnuclear distribution of TFIID versus TAF3 is correlated with their selective occupancies at the $M y o D$ promoter in myoblasts. In contrast, in myotubes, where TFIID is lost, MyoD becomes repositioned to the nuclear interior, where TAF3 resides, and this is accompanied by an increased occupancy of TAF3 at the $M y o D$ promoter. Furthermore, by ectopically modulating the locations of the $M y o D$ promoter and/or TAF3 protein, we show that their spatial segregation is functionally linked to the selective occupancy of TAF3 at the MyoD promoter. We also found that specific recognition and high-affinity binding by the TAF3 plant homeodomain (PHD) finger to the histone mark H3K4Me3 may be required for the sequestration of TAF3 to the nuclear interior. These studies suggest that differential nuclear compartmentalization of target genes and regulatory factors may provide an additional mechanism for promoter selectivity during differentiation of animal cells.

\section{Results}

\section{Nuclear locations of key myogenic genes in myoblasts}

To begin this study, we determined the positions of $M y o D$ by immuno-DNA FISH in mouse $\mathrm{C} 2 \mathrm{C} 12$ myoblasts. Visualization of the nuclear periphery by an antibody against nuclear Lamin B shows that the $M y o D$ gene is preferentially localized to the nuclear periphery (Fig. 1A,B;
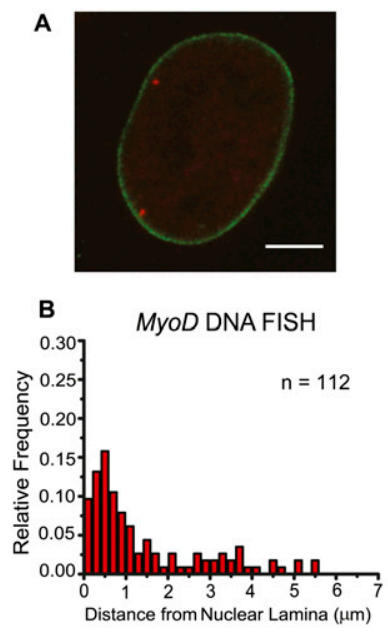

C

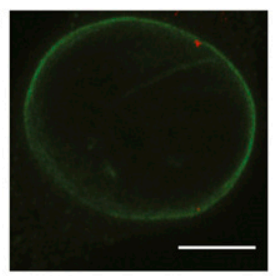

D MyoD RNA FISH

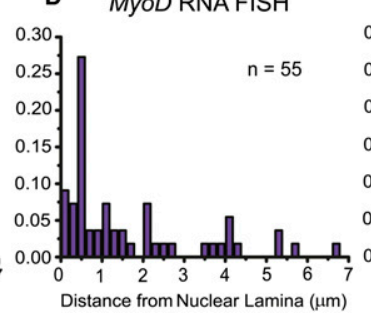

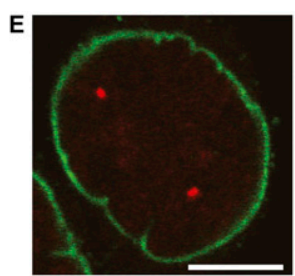

F Myogenin DNA FISH

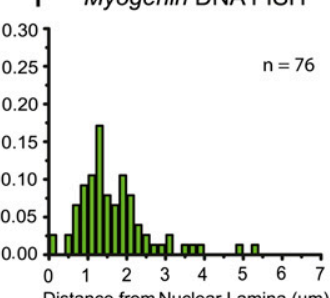

Figure 1. FISH analysis of $M y o D$ and Myogenin gene loci in $\mathrm{C} 2 \mathrm{C} 12$ myoblasts. $(A, B)$ DNA FISH of $M y o D$ gene (red) in myoblasts. (A) The nuclear periphery is highlighted by anti-Lamin B (green). Other micrographs follow the same color scheme. $(B)$ Frequency histogram versus the distance of $M y o D$ genes from the NL. $B, D$, and $F$ are frequency histograms versus distance from genes to the $\mathrm{NL}$ in the corresponding FISH experiments shown in $A, C$, and $E$, respectively. $(C, D)$ RNA FISH of $M y o D$ gene in myoblasts. Kolgomorov-Smirnov (K-S) test of distributions in $B$ and $D: P=0.50$. $(E, F)$ DNA FISH of the Myogenin gene (red) in myoblasts. K-S test of distributions in $B$ and $F: P<0.001$. Fisher's exact tests of $M y o D$ and Myogenin genes that are located within $0.6-, 0.8-$, or $1.0-\mu \mathrm{m}$ distance to the NL: $P<0.0001$ in all cases. Bars, $5 \mu \mathrm{m}$. 
Supplemental Fig. S1A), in agreement with a previous study (Lee et al. 2006). Importantly, nascent $M y o D$ transcripts were visualized through immuno-RNA FISH, and these transcripts were also located at the nuclear periphery (Fig. 1C,D), confirming that the peripherally localized $M y o D$ genes are transcriptionally active. In contrast, the Myogenin gene is inactive in myoblasts, and we found that this "later" gene is located largely to the nuclear interior in myoblasts (Fig. 1E,F; Supplemental Fig. S1B). Chromatin immunoprecipitation (ChIP) assays confirm that RNA polymerase II ( $\mathrm{Pol}$ II) occupancy is enhanced at the $M y o D$ promoter relative to the $M y o G$ promoter in myoblasts (Supplemental Fig. S1C). These findings reveal that two key temporally regulated myogenic genes are differentially localized within the myoblast nucleus, posing intriguing potential mechanisms for their differential regulation.

\section{Localizing general transcription factors in myoblasts}

The $M y o D$ gene is actively transcribed in myoblasts by the codependent action of upstream activators and requisite core promoter recognition complexes (Hu et al. 2008). In the case of $M y o D$ transcription in myoblasts, the prototypic core factor TFIID occupies the $M y o D$ promoter. Because the $M y o D$ gene is preferentially localized at the nuclear periphery in myoblasts (Fig. 1), we set out to visualize which components of the transcription apparatus are colocalized at the nuclear periphery. We investigated the localizations of Pol II and TFIID by immunofluorescence staining and high-resolution multicolor confocal microscopy. As expected, Pol II is diffusely localized throughout the nucleoplasm, including the zone at the nuclear periphery in myoblasts (Fig. 2A,B). Furthermore, TAF11, TAF4, and TBP subunits of TFIID
A Pol II (4H8)
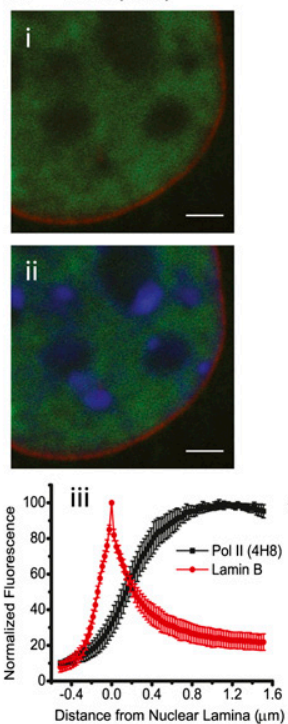

E TBP
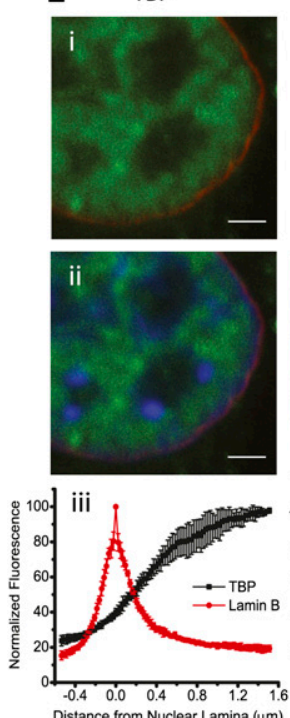

Distance from Nuclear Lamina $(\mu \mathrm{m})$
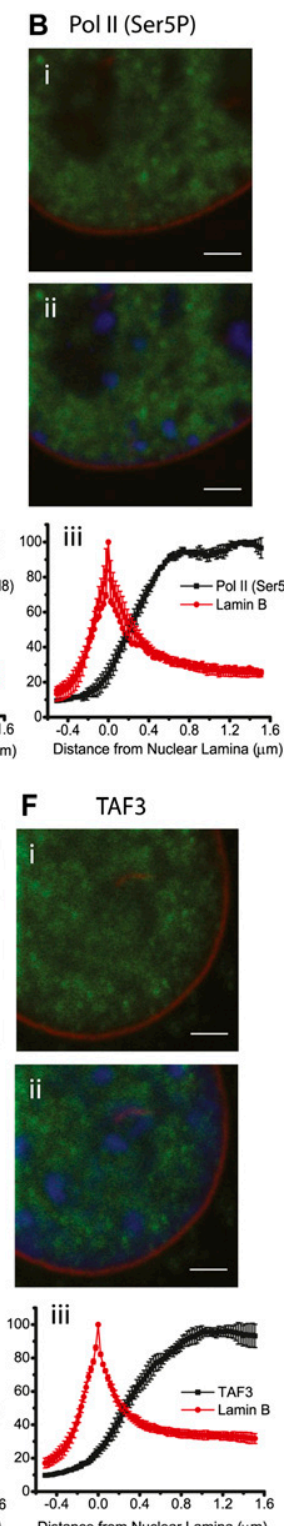
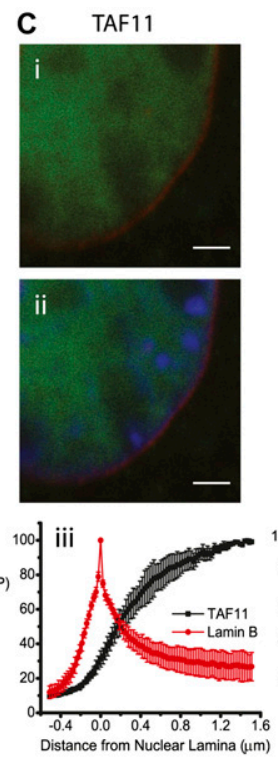

G
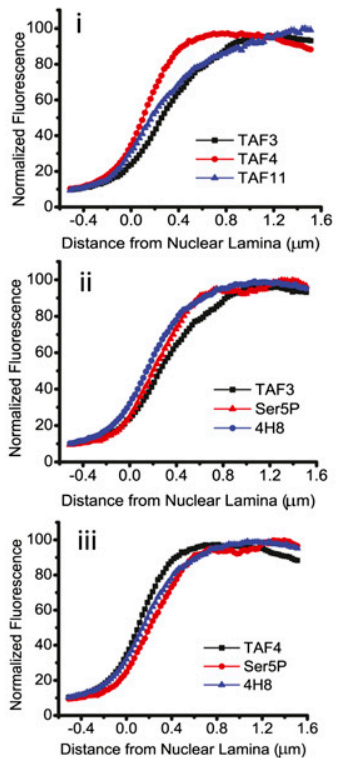

Figure 2. Immunofluorescence staining of several components of core transcription machinery in $\mathrm{C} 2 \mathrm{C} 12$ myoblasts. (A, panel i) RNA polymerase II stained with $4 \mathrm{H} 8$ antibody (green) with anti-Lamin B (red). (Panel ii) The image in panel $i$ superimposed by DNA staining with Hoechst 33342 (blue). (Panel iii) The radial intensity plot integrated over the entire contour of nuclear lamin from representative images $(n=8)$. Error bars are standard deviations. The same organization follows for the rest of subpanels. (B) Ser5-phosphorylated RNA Pol II $(n=3)$. $(C)$ TAF11 $(n=3)$. (D) TAF4 $(n=3) .(E)$ TBP $(n=3) .(F)$ TAF3 $(n=6) .(G)$ Intensity plots of antibody staining signals in comparison: (Panel i) TAF3, TAF4, and TAF11. One-way ANOVA test of GFP intensity values between 0 and $0.4 \mu \mathrm{m}$ from the lamina: $P<0.001$. (Panel ii) TAF3, Pol II (4H8), and Pol II (Ser5P): $P<0.04$. (Panel iii) TAF4, Pol II (4H8), and Pol II (Ser5P): $P<0.04$. Bars, $2 \mu \mathrm{m}$. 
are diffusely localized inside the nucleoplasm of myoblasts, and careful examination confirms that these immunostaining signals are still detectable at the boundary of the nucleus, labeled by an antibody against nuclear Lamin B (Fig. 2C-E). Because TAF4 is an essential component of the TFIID complex (Wright et al. 2006), it is likely that holo-TFIID is not only distributed throughout the nucleoplasm, but is also present at the nuclear periphery. Our DNA staining profiles usually show a peak close to the lamina signal (Supplemental Fig. S2), and this observation is consistent with earlier studies visualizing dense DNA structures at the nuclear periphery by electron microscopy (Davies 1967), and serves as a control to ascertain appropriate alignment of multiple image channels in our analysis. It was reported that heterochromatin regions allow the placement of macromolecules with molecular weights of $\sim 500 \mathrm{kDa}$ (Bancaud et al. 2009), which is consistent with our observations that TAF4 and Pol II are present at the nuclear periphery.

In contrast to Pol II and TFIID, myoblasts stained with TAF3 antibodies revealed a clearly distinguishable region immediately adjacent to the NL with measurably lower immunofluorescence levels (Fig. 2F). The various antibodies against TAF3 used in these nuclear staining studies were first affinity-purified and extensively characterized (Supplemental Fig. S3A,B). Integrated radial intensity profiles indicate that the distance of half-maximum of TAF3 signals to the center of the lamin signal is $\sim 400 \mathrm{~nm}$ (Fig. 2F, panel iii); this distance is larger than those measured for TFIID subunits or Pol II $(\sim 100-200$ $\mathrm{nm}$ ) (Fig. 2A-E), and is well within our optical resolution limits. We further found statistically significant differences among the mean intensity values at the nuclear periphery between TAF3 versus TAF4/TAF11 subunits (Fig. 2G, panel i), as well as between TAF3 versus Pol II (Fig. 2G, panel ii). These cell imaging results are consistent with our previous biochemical observation that TAF3 is a substoichiometric subunit associated with the TFIID complex (Liu et al. 2008). Interestingly, the TAF4 signal appears to be distinct from that of Pol II and distributes "closer" to the nuclear periphery (Fig. 2G, panel iii). We also found that H3K9Me3 staining is detectably enriched at the nuclear periphery in myoblasts, while H3K4Me3 staining is slightly shifted to the nuclear interior (Supplemental Fig. S4A). Taken together, our imaging analysis demonstrates significantly differential distributions for core transcription components at the nuclear periphery in $\mathrm{C} 2 \mathrm{C} 12$ myoblasts, and we observed that a shell or region directly adjacent to the nuclear periphery is substantially depleted of TAF3 relative to the nuclear interior.

Extending our studies to living cells, we directly visualized a distinct layer of reduced GFP-TAF3 fluorescence intensity at the nuclear periphery (Supplemental Fig. S5A, panels iv,v). In contrast, GFP-tagged Rpb9, TAF11, and human TAF1 each showed fluorescence relatively uniformly distributed throughout the nucleoplasm, including the region adjacent to or at the nuclear periphery (Supplemental Fig. S5A, panels i-iii). These live-cell imaging studies are consistent with our immunofluorescence results, and support the notion that the lower levels of TAF3 observed at the nuclear periphery likely reflect its steady-state intranuclear distributions in living myoblasts. Immunostaining of TRF3 proteins suggests that they might also distribute to the nuclear interior (Supplemental Fig. S3F). In primary myoblasts, the MyoD gene is also largely localized adjacent to the nuclear periphery and the Myogenin gene is largely localized adjacent to the nuclear interior, while TAF3 is localized largely to the nuclear interior and shows no significant difference from its distribution in C2C12 cells (Supplemental Fig. S6). There is also a high enrichment of H3K9Me3 and a slight decrease of Pol II levels at the nuclear periphery (Supplemental Fig. S6). Hence, the spatial distributions of $M y o D$ gene and core transcription components in the in vivo-derived primary cells are largely consistent with our findings in C2C12 myoblasts.

The observation that Pol II and canonical TFIID subunits are present at the nuclear periphery, where TAF3 is underrepresented, supports the notion that the alternative core factor TAF3 may be spatially segregated from the peripherally localized, actively transcribed $M y o D$ gene. This intriguing finding leads us to speculate whether the subnuclear segregation of TAF3 from the $M y o D$ gene may influence or perhaps preclude its association with the MyoD promoter.

\section{PALM imaging of transcription factor localization in myoblasts}

The nuclear periphery is a challenging subdomain of the nucleus to target for optical microscopy because its radial dimensions and lateral microdomains approach the diffraction limit of conventional optical microscopy. With three-dimensional (3D) structured illumination microscopy, nuclear periphery components could be better resolved in both radial and lateral dimensions compared with confocal or deconvolution microscopy (Schermelleh et al. 2008). However, precisely comparing locations of distinct transcription factors at the nuclear periphery would best be served by methods that can visualize and resolve individual molecules within the context of the nucleus. We adapted dual-color PALM (Betzig et al. 2006; Bates et al. 2007; Shroff et al. 2007) and developed a procedure to image individual transcription factor molecules at the nuclear periphery in $100-\mathrm{nm}$ sections of undifferentiated and differentiated C2C12 cells after high-pressure freezing, freeze substitution (HPF/FS), and embedding with LR White resin (see the Materials and Methods for details). The LmnA-PSCFP2 and LmnB1-mEos2 proteins were used as markers for delineating the nuclear periphery, and they were well aligned in the radial dimension, indicating a correct image registration of this dual-color PALM assay (Fig. 3A,B). Lamin A and Lamin B1 were resolved laterally along the nuclear periphery, agreeing with a previous observation of NL in HeLa cells using antibody staining (Shimi et al. 2008).

As expected, many molecules of mEos2-tagged TAF11 and Rpb9 (representing TFIID and Pol II) can be found 

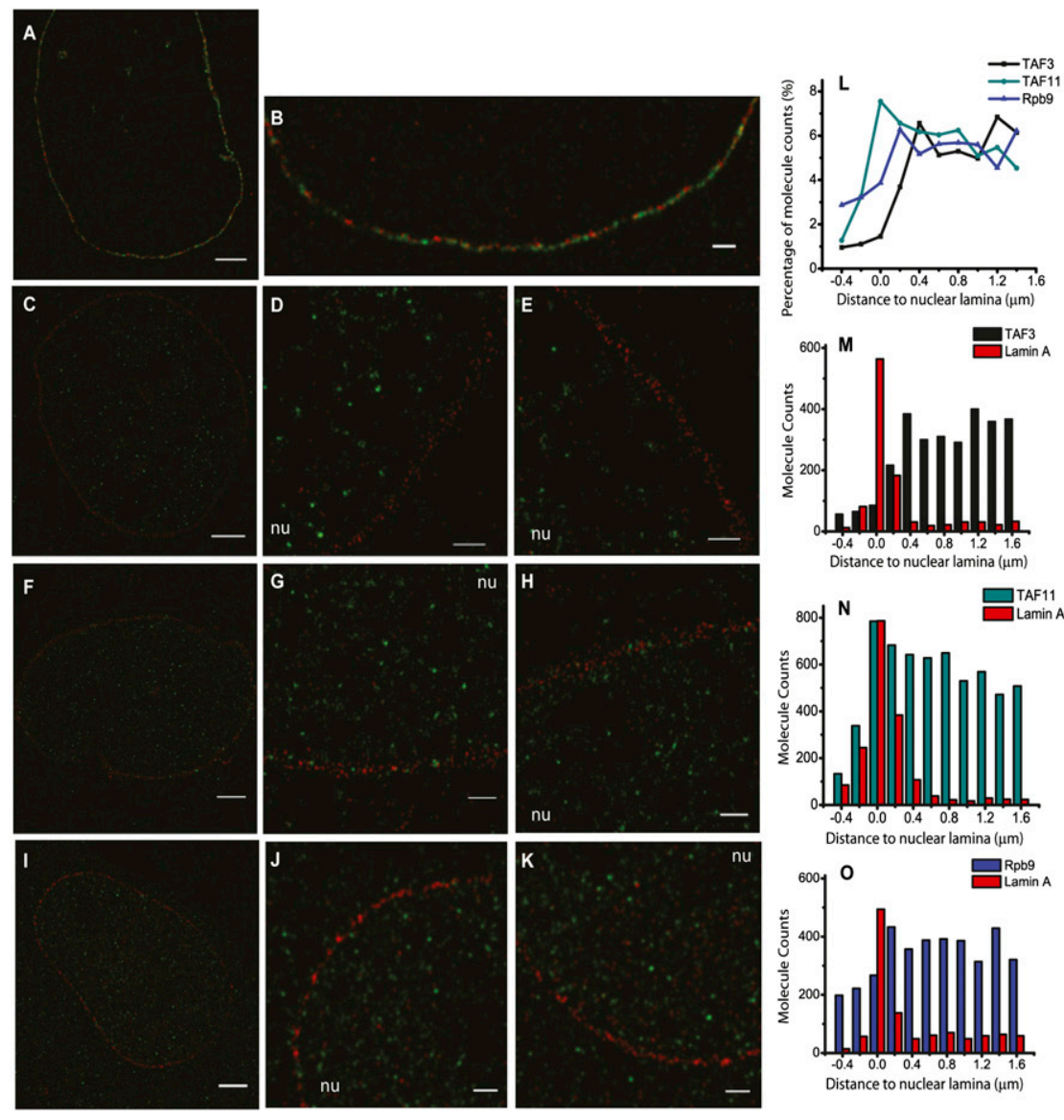

Figure 3. Dual-color PALM imaging of C2C12 myoblast cell sections after HPF/ FS. $(A, B)$ Lamin B1-mEos2 (green) and Lamin A-PSCFP2 (red). The alignment of two lamina components indicates the spatial precision of this dual-color PALM assay. $(C-E)$ TAF3-mEos2 (green) and Lamin A-PSCFP2 (red). $(D, E)$ Enlarged images of two subregions of the image in $C$. nu labels the intranuclear region. $(F-H)$ TAF11-mEos2 (green) and Lamin A-PSCFP2 (red). $(I-K)$ Rpb9-mEos2 (green) and Lamin A-PSCFP2 (red). Bars: $A, C, F, I, 2 \mu \mathrm{m} ; B, D, E, G, H, J, K, 500$ $\mathrm{nm}$. $(L-O)$ Counting molecules at the nuclear periphery. $L$ shows the percentage of counted molecules within each 200-nm "layer" from the nuclear periphery to the nuclear interior as a fraction of the total number of counted molecules. Molecule counts for TAF3, TAF11, Rpb9, and Lamin A molecules from $C, F$, and $I$ are shown in $M, N$, and $O$, respectively. localized at the nuclear periphery of $\mathrm{C} 2 \mathrm{C} 12$ myoblasts (i.e., within $500 \mathrm{~nm}$ of the NL labeled by LmnA-PSCFP2), confirming that our sample preparation and imaging methods do not generally impede the detection of transcription factor molecules at the nuclear periphery (Fig. 3F-K). In striking contrast, TAF3-mEos2 mostly exhibits as individual puncta within the nuclear interior, and measurably fewer TAF3 molecules are present at the nuclear periphery (within $500 \mathrm{~nm}$ from the NL) (Fig. 3C-E,L). This finding supports our immunostaining results (Fig. 2F; Supplemental Fig. S3C) as well as livecell imaging of GFP- and mEos2-tagged TAF3 (Supplemental Fig. S5A). Importantly, PALM imaging has overcome the "blurred" images at the nuclear periphery due to limits in optical resolution, dramatically enhanced the image contrast, and enabled direct counting of individual molecules or complexes (Fig. 3M-O). Thus, employing three complementary methods of imaging transcription factors, we have provided compelling evidence that there is a deficit of TAF3 versus TFIID molecules at the nuclear periphery relative to the nuclear interior. Many transcription factors were found to reside throughout the nucleoplasm, including the nuclear periphery, and this is, to our knowledge, the first demonstration of an alternative core transcription component that can be sequestrated away from the nuclear periphery.
Functional tests on the spatial segregation between the MyoD gene and the TAF3 protein

To address the functional consequences of differential spatial distributions of TFIID and particularly TAF3 relative to the nuclear periphery, we directly manipulated the locations of $M y o D$ transgenes and TAF3 proteins in myoblasts. First, we generated a stable cell line containing the $M y o D$ promoter with an EGFP reporter (Fig. 4A). DNA FISH confirmed that the MyoD::EGFP transgene was localized almost exclusively to the nuclear interior (Fig. 4B,C). EGFP fluorescence was also detected in these cells harboring the transgene, indicating that the $M y o D$ transgene promoter is active (data not shown). We next used ChIP to check the occupancy of TAFs at the $M y o D:: E G F P$ transgene and at the native $M y o D$ promoter. The immunoprecipitated DNA was quantified through quantitative PCR (qPCR) with primer sets specific for the transgene and the native gene, respectively, and was normalized to input DNA. This normalization took into account the different copy numbers of the transgene (estimated to be $<20$ ) relative to the native gene. Both TAF1 and TAF3 are detectably enriched at the transgene promoter; however, TAF3 is not enriched at the native $M y o D$ promoter (Fig. 4D). We note that there was no significant increase in TAF1 occupancy at the MyoD::EGFP transgene promoter, suggesting that the detected ChIP 

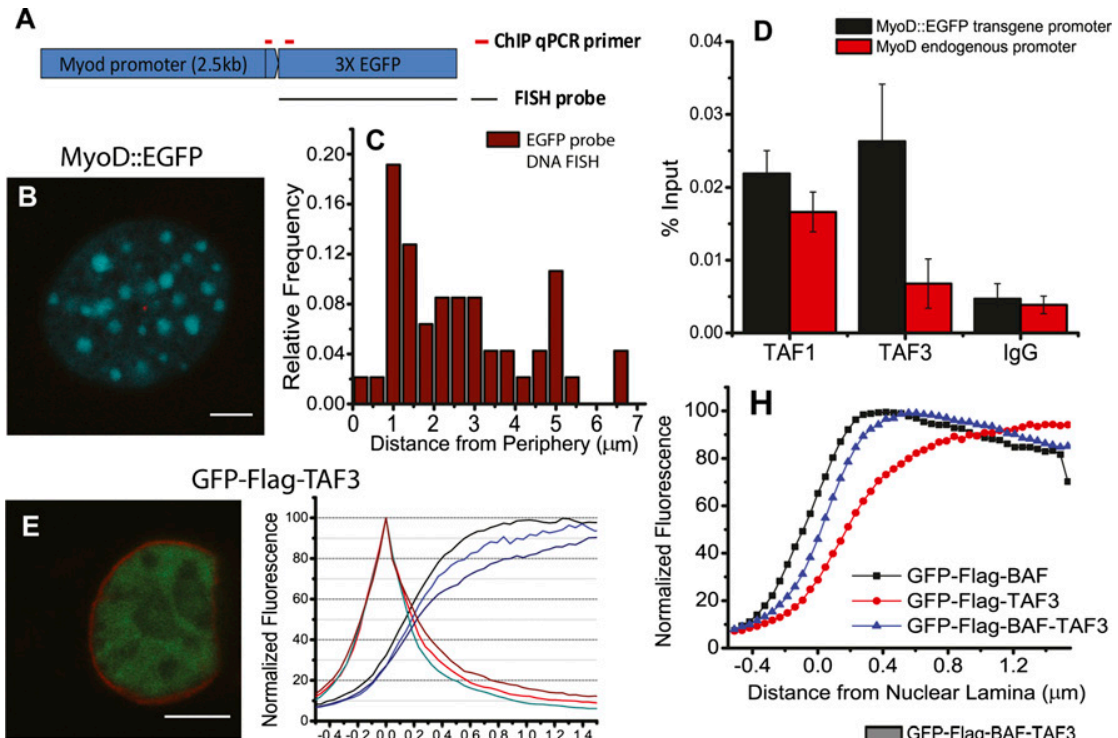

GFP-Flag-TAF3

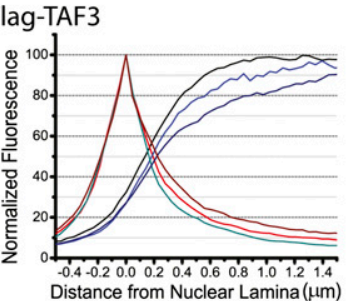

GFP-Flag-BAF
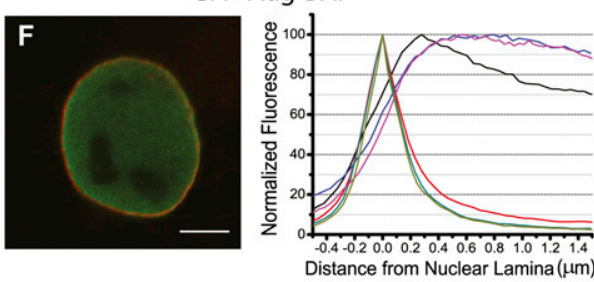

GFP-Flag-BAF-TAF3
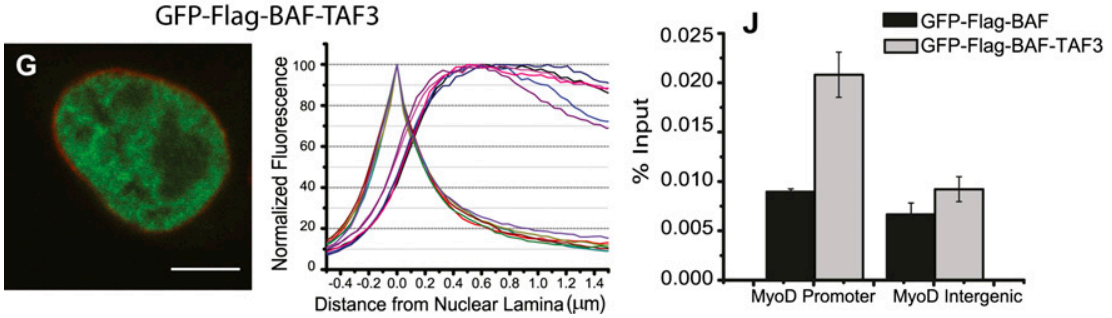

Figure 4. Functional tests on the spatial segregation between the $M y o D$ promoter and the TAF3 protein. (A) Experimental scheme of generating a MyoD::3xEGFP transgene with the locations of the ChIP qPCR primer and the FISH probe. $(B) \mathrm{A}$ representative image of DNA FISH visualizing the MyoD::3xEGFP transgene. DNA stain is in cyan, and FISH signal is in red. $(C)$ Histogram of distances of FISH signals from the nuclear periphery. K-S test of distributions of the transgene $(C)$ versus native MyoD (Fig. 1B): $P<0.001$. (D) ChIP assay of TAF1 and TAF3 occupancy at the $M y o D:: 3 \times E G F P$ transgene promoter and the native $M y o D$ promoter. All error bars are standard errors of the means (SEMs; $n=$ 4). Student's $t$-tests for ChIP signals from anti-TAF3 versus IgG: $P<0.05$ on transgene promoter, and $P=0.44$ on native gene promoter. $(E-G)$ Representative images and intensity profiles of GFP-3xFlagTAF3 $(n=3)(E)$, GFP-3xFlag-BAF $(n=3)$ $(F)$, and GFP-3xFlag-BAF-TAF3 $(n=6)(G)$ expressed in $\mathrm{C} 2 \mathrm{C} 12$ myoblasts. Intensity profiles of lamin and GFP fluorescence from multiple cells were plotted in the same graph. Bars, $5 \mu \mathrm{m}$. (H) Intensity plots of averaged GFP fluorescence shown in the same plot. One-way ANOVA tests of GFP fluorescence $(0-0.4 \mu \mathrm{m}$ from the lamina): $P<0.005$ for TAF3 versus BAF-TAF3, and $P=0.10$ for BAF-TAF3 versus BAF. $(I)$ Anti-Flag ChIP assay on C2C12 cells transfected with GFP-Flag-BAF-TAF3 versus with GFP-Flag-TAF3 at the MyoD promoter $(n=4)$. Student's $t$-tests for ChIP signals on $M y o D$ promoter versus an intergenic region: $P=0.12$ on GFP-Flag-TAF3 cells, and $P<0.02$ for GFP-Flag-BAF-TAF3 cells. (J) Anti-Flag ChIP assay on C2C12 cells transfected with GFP-Flag-BAF versus with GFP-Flag-BAF-TAF3 $(n=3)$. Student's $t$-tests for ChIP signals on MyoD promoter versus an intergenic region: $P=0.13$ on GFP-FlagBAF cells, and $P<0.02$ for GFP-Flag-BAF-TAF3 cells.

signals do not merely reflect a higher copy number of transgene DNA, and indeed reflect specific protein-DNA associations. This $M y o D$ transgene experiment thus suggests that, in myoblasts, endogenous TAF3 might very well have been able to bind the $M y o D$ promoter if $M y o D$ had not been segregated to the nuclear periphery but had instead been allowed to reside within chromosome regions that largely locate to the nuclear interior.

However, we could not rule out the possibility that the $M y o D$ transgene repeats that we generated merely increased local concentrations and therefore the chances for TAF3 association. To address this issue, we performed a reciprocal experiment to test whether the native, two copies of the MyoD promoter can associate with TAF3, if we drive TAF3 to be ectopically expressed and present at the nuclear periphery. We previously found, by immunofluorescence staining, that endogenous TAF3 protein is located primarily in the nuclear interior. Using PALM imaging of GFP-tagged TAF3, we found that modestly overexpressed TAF3 is still largely sequestered to the nuclear interior (Figs. 2, 3). We therefore used TAF3 fused to barrier-to-autointegration factor (BAF) as a module to target the location of TAF3 to the nuclear periphery. BAF is an $\sim 10-\mathrm{kDa}$ protein that binds to the LEM domain proteins at the inner nuclear membrane (INM), and is thought to bridge INM proteins and chromatin (SeguraTotten and Wilson 2004). Consistent with our previous imaging results, GFP-Flag-TAF3 is noticeably sequestrated from the nuclear periphery, with the radial position of the half-maximum GFP signal $\sim 0.2 \mu \mathrm{m}$ to the lamin signal (from the inner side) (Fig. 4E). In contrast, GFPFlag-BAF is localized throughout the nucleoplasm and enriched at the nuclear periphery, with the position of the half-maximum GFP signal to be approximately $-0.1 \mu \mathrm{m}$ (to the lamin center from the outer side) (Fig. 4F). Importantly, the GFP-Flag-BAF-TAF3 fusion protein was 
no longer segregated from the nuclear periphery; the halfmaximum GFP signal is approximately right at the lamin center (Fig. 4G,H). We next performed ChIP experiments using myoblasts expressing these fusion proteins with higher or lower abundance at the nuclear periphery. As expected, GFP-Flag-TAF3 is not significantly enriched at the $M y o D$ promoter, while GFP-Flag-BAF-TAF3 showed a twofold to threefold enrichment at the $M y o D$ promoter over an intergenic control region (Fig. 4I). We also note that GFP-Flag-BAF is not detectably enriched at the $M y o D$ promoter or intergenic control region (Fig. 4J), suggesting that the enhanced ChIP signals that we observed are likely not due to the artificial recruitment of the fusion proteins to the $M y o D$ promoter by BAF itself. Therefore, the subnuclear localization of ectopically expressed TAF3 appears to be linked to its association with the native $M y o D$ promoter such that, when expressed TAF3 is targeted to the nuclear periphery, it can occupy the $M y o D$ promoter. Hence, both experimental approaches leading to the loss of this spatial segregation result in an increased TAF3 occupancy at the MyoD promoter. These findings, taken together, suggest that the subnuclear spatial segregation between TAF3 and the $M y o D$ promoter in myoblasts may be functionally important in influencing the accessibility of TAF3 to the MyoD promoter.

\section{Which factors might sequester TAF3 from the nuclear periphery?}

To test whether TAF3 localization is dependent on transcription activity, we treated C2C12 myoblasts with $\alpha$-amanitin. This treatment abolished nascent transcript labeling as detected by bromo-uridine triphosphate (BrUTP) incorporation, except at a few loci presumably being transcribed by RNA Pol I, which is resistant to low levels of $\alpha$-amanitin (Fig. 5A). Surprisingly, TAF3 remains localized largely to the nuclear interior and sequestered from the nuclear periphery under this condition (Fig. 5B). Thus, Pol II inhibition does not appear to

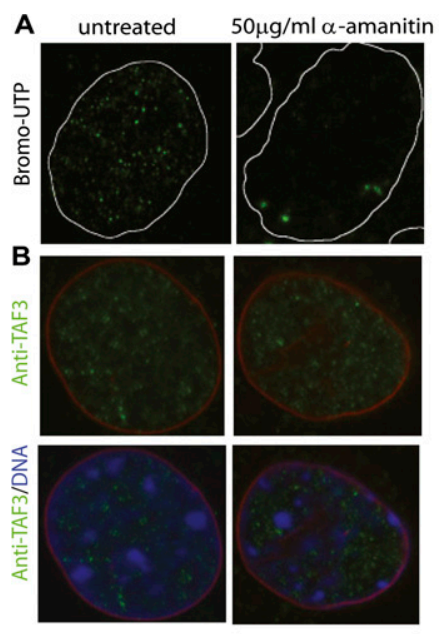

C

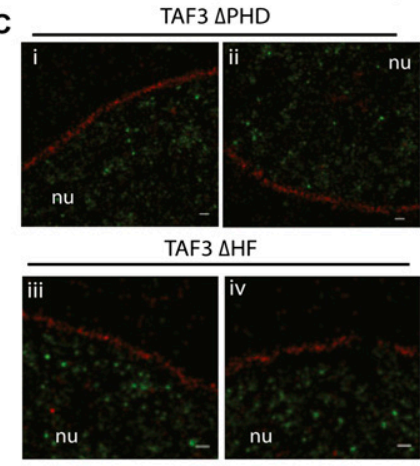

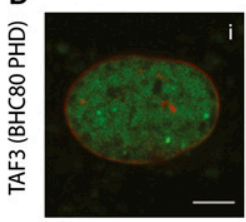
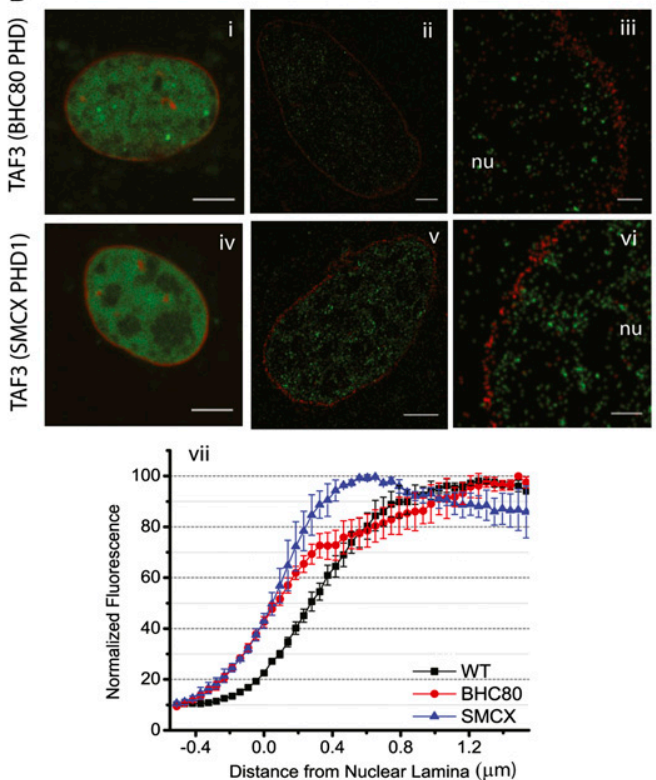

E
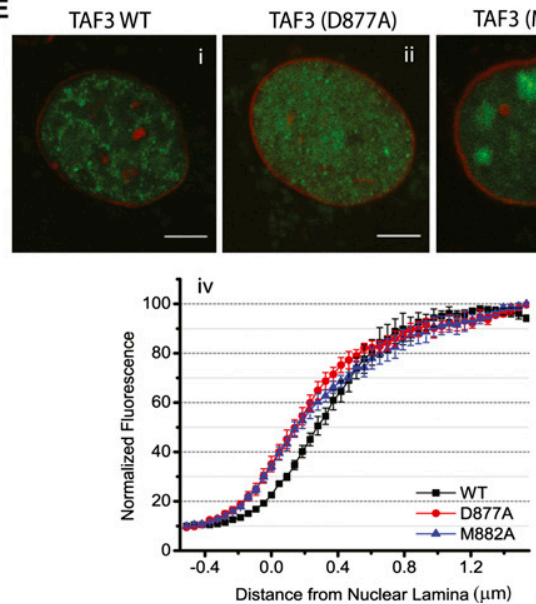

Figure 5. Potential mechanisms for the sequestration of TAF3 from the nuclear periphery. (A) Br-UTP incorporation assay in $\mathrm{C} 2 \mathrm{C} 12$ myoblasts untreated or treated with $50 \mu \mathrm{g} / \mathrm{mL} \alpha$-amanitin. Nascent transcripts were labeled green with anti-BrdU. The white line outlines the nuclear boundary. (B) Anti-TAF3 immunostaining (green) of $\mathrm{C} 2 \mathrm{C} 12$ myoblasts untreated or treated with $50 \mu \mathrm{g} / \mathrm{mL} \alpha$-amanitin. Lamin $\mathrm{B}$ is labeled in red, and DNA is labeled in blue. (C) Localization of TAF3 deletion mutants. (Panels i,ii) TAF3 mutant deleted of Cterminal PHD finger, labeled with mEos2 (green), and visualized together with Lamin A-PSCFP2 (red) by dual-color PALM. (Panels iii,iv) TAF3 mutant deleted of $\mathrm{N}$-terminal HF domain. nu labels the intranuclear region. Bars, $200 \mathrm{~nm} .(D)$ Localization of TAF3 mutants that contain PHD fingers with altered specificities. (Panel i-iii) TAF3 (BHC80PHD), which recognizes H3K4Me0. (Panels iv-vi) TAF3 (SMCXPHD1), which recognizes H3K9Me3. Panels $i$ and iv are confocal images (bars, $5 \mu \mathrm{m}$ ), and panels ii, iii, $v$, and $v i$ are PALM images (bars: ii, $v, 2$ $\mu \mathrm{m}$; iii,vi, $500 \mathrm{~nm}$ ). (Panel vii) Radial intensity profiles of the two PHD finger swap mutants and wild-type TAF3. One-way ANOVA test of GFP intensity values between 0 and $0.4 \mu \mathrm{m}$ from the lamina: $P<$ 0.001. (E) Localization of TAF3 wild-type protein (panel i) and PHD finger point mutants (panels ii,iii). (Panel iv) Radial intensity profiles of the two PHD point mutants and wild-type TAF3. One-way ANOVA test of GFP intensity values between 0 and $0.4 \mu \mathrm{m}$ from the lamina: $P<0.04$. Bars, $5 \mu \mathrm{m}$. Error bars are SEMs ( $n=3$ for each curve). 
alter the steady-state nuclear distribution of TAF3, and active Pol II transcription is likely not required for this differential localization of TAF3.

To explore alternative mechanisms that may impede TAF3 access to the nuclear periphery, we examined the nuclear distribution of a TAF3 mutant that lacks the $\mathrm{N}$-terminal histone fold (HF) and a second mutant that lacks the C-terminal PHD in myoblasts by PALM. The TAF3 $\triangle$ HF mutant retained its proper localization to the nuclear interior, similar to full-length TAF3, while the TAF3 $\triangle$ PHD mutant was found at a significantly higher frequency at the nuclear periphery compared with wild-type TAF3 and TAF3 $\triangle$ HF (Fig. 5C). Because TAF3 has been reported to bind the histone modification mark H3K4Me3 via its PHD finger (Vermeulen et al. 2007; van Ingen et al. 2008), we further tested whether the specific recognition of H3K4Me3 by the TAF3 PHD domain is required for TAF3 localization. Fusion proteins were generated consisting of TAF3 $\triangle \mathrm{PHD}$ linked to PHD finger domains from BHC80 and SMCX. These two mutant PHD fingers were reported to specifically recognize $\mathrm{H} 3 \mathrm{~K} 4 \mathrm{Me} 0$ and H3K9Me3, respectively (Iwase et al. 2007; Lan et al. 2007). We noticed that $\mathrm{H} 3 \mathrm{~K} 9 \mathrm{Me} 3$ is enriched at the nuclear periphery in $\mathrm{C} 2 \mathrm{C} 12$ cells (Supplemental Fig. S4). Strikingly, TAF3 (BHC80PHD) and TAF3 (SMCXPHD1) both become localized throughout the nucleoplasm, including the nuclear periphery (Fig. 5D), with SMCXPHD1 showing a noticeable enrichment at the nuclear periphery (Fig. 5D, panels iv-vii). The radial fluorescence intensity plot confirms the loss of segregation from the nuclear periphery in these two PHD domain swap mutants of TAF3, and indicates a higher fluorescence level at the periphery for the TAF3 (SMCXPHD1) mutant (Fig. 5D, panel vii). This result suggests that the specific recognition of histone marks by the PHD domain of TAF3, but maybe not the general structure of PHD fingers, is likely required for the sequestration of TAF3 from the nuclear periphery. Additionally, although $\alpha$-amanitin treatment alters the Pol II staining patterns in $\mathrm{C} 2 \mathrm{C} 12$ myoblasts, the H3K4Me3 staining signals remain abundant (Supplemental Fig. S7), which is consistent with the finding that TAF3 retains an internal localization under $\alpha$-amanitin treatment.

If chromatin binding can help establish the subnuclear localization of TAF3, one would suggest that the majority of TAF3 molecules may be chromatin-associated at a given short time interval, because it is expected that nonchromatin-associated, diffusing TAF3 molecules would be relatively uniformly distributed in the nucleus. The binding equilibrium would predict that a lower $K_{d}$ should lead to a larger fraction of chromatin-associated TAF3. Notably, the TAF3 PHD domain is reportedly the strongest H3K4Me3 binder, with an affinity of $\sim 0.3 \mu \mathrm{M}$ (van Ingen et al. 2008). To test whether differential binding affinities of the PHD domain to H3K4Me3 can affect TAF3 localization, we examined some TAF3 point mutants. The M882A mutation was reported to abolish the TAF3PHD-H3K4Me3 interaction (Vermeulen et al. 2007), and structural analysis showed that this mutant severely disrupts the H3K4Me3-binding pocket (van Ingen et al. 2008). Here we found that the TAF3 (M882A) mutant is distributed throughout the nucleoplasm, including the nuclear periphery, and accumulates at the nucleolus, possibly through other sequestration mechanisms (Fig. 5E, panel iii; Supplemental Fig. S5B). The TAF3 D887A mutant bears a PHD domain with an $\sim 16$-fold lower affinity $\left(\mathrm{K}_{\mathrm{d}} \sim 5 \mu \mathrm{M}\right)$ to H3K4Me3 compared with wildtype TAF3 (van Ingen et al. 2008), and this mutant also shows diminished sequestration from the nuclear periphery (Fig. 5E, panel ii; Supplemental Fig. S5B). Both PHD point mutants of TAF3 have radial intensity profiles that are distinguishable from wild-type TAF3 and shift toward the nuclear periphery (Fig. 5E, panel iv). Although the actual in vivo scenario is likely more complex than the binding equilibrium, the specific recognition of H3K4Me3 by the PHD domain and its relatively high binding affinity (submicromolar $\mathrm{K}_{\mathrm{d}}$ ) provide an intriguing explanation for the sequestration of TAF3 away from the nuclear periphery.

\section{Localizing genes and transcription factors in myotubes}

We further tracked the positions of $M y o D$ and Myogenin that are actively transcribed in myotubes where TFIID has been largely eliminated but TAF3 is retained and serves as the alternative core factor (Deato and Tjian 2007). In contrast to the situation in myoblasts, we now find by DNA FISH that $M y o D$ in myotubes is localized predominantly to the nuclear interior (Fig. 6A). Not surprisingly, the Myogenin gene that is only turned on at this later stage of myogenesis remains localized at the nuclear interior in myotubes, where it was also predominantly found in myoblasts (Fig. 6A). In addition, we were able to detect transcripts of $M y o D$ and Myogenin by RNA FISH, suggesting that active transcription of both genes occurs in the nuclear interior of myotubes (Fig. 6A). By ChIP analysis, we found that there is a twofold increase in Pol II occupancy at the $M y o D$ promoter, and $>10$-fold increase in Pol II occupancy at the Myogenin promoter in myotubes relative to myoblasts (Supplemental Fig. S1C). ChIP assays further show that TAF3 is detectable at the Myogenin promoter in myotubes (Deato and Tjian 2007), and that TAF3 occupancy at the $M y o D$ promoter increased by approximately eightfold in myotubes relative to myoblasts (Fig. 6B).

As reported previously, TFIID is largely abolished in myotubes, and, indeed, we failed to detect subunits of TFIID at either the nuclear periphery or the nuclear interior in myotubes (data not shown). Pol II and TAF3 show a diminished immunostaining signal at the nuclear periphery relative to the nuclear interior (Fig. 6C), while TRF3 appears to be largely localized to the nuclear interior (data not shown). H3K9me3 mark remains enriched at the nuclear periphery (Supplemental Fig. S4), indicating that the nuclear periphery in myotubes is accessible to antibody staining. Distances between half-maximal immunofluorescence signals of Pol II and TAF3 to the center of NL signals are $500-750 \mathrm{~nm}$ in myotubes (Fig. 6C). Dual-color PALM imaging of myotubes also demonstrates that there are fewer TAF3 


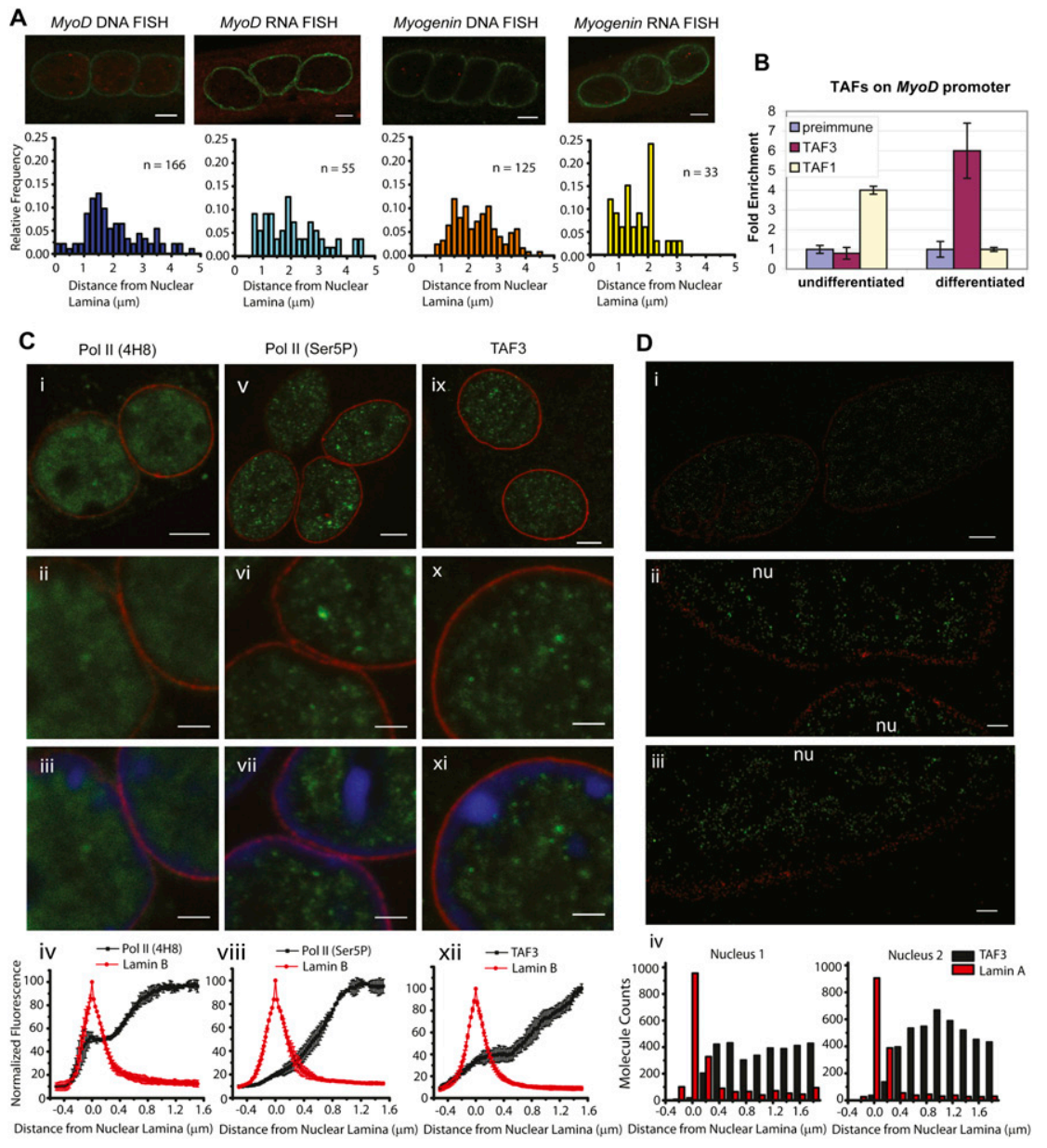

Figure 6. Localization of genes and transcription factors in myotubes. $(A)$ DNA FISH and RNA FISH images and histograms of $M y o D$ and Myogenin genes in myotubes ([red] FISH signals). Anti-Lamin B (green) marks the NL. Bars, $5 \mu \mathrm{m}$. K-S test of $M y o D$ gene distributions in myotubes and myoblasts (Fig. 1B): $P<0.001$. (B) ChIP assay to measure the occupancies of TAF3 versus TAF1 on the MyoD promoter in undifferentiated and differentiated C2C12 cells. Error bars represent SEMs $(n=3)$. Student's $t$-tests for TAF3 occupancies before and after differentiation: $P<0.03$; for TAF1 occupancies before and after differentiation: $P<0.001$. (C) Immunofluorescence detection of Pol II and TAF3 in myoblasts. Antibodies are labeled in green, and Lamin B is labeled in red. Panels ii, vi, and $x$ are the enlarged images of a subregion in panels $i, v$, and $i x$, respectively. Panels iii, vii, and $x i$ are the images in panels $i i, v i$, and $x$ superimposed by DNA staining with Hoechst 33342 (blue), respectively. Bars: panels $i, v, i x, 5 \mu \mathrm{m}$; remaining panels, $2 \mu \mathrm{m}$. Panels $i v$, viii, and xii are the radial intensity plot integrated over the entire contour of nuclear lamin from representative images $(n=2,2$, and 4 , respectively). (D). PALM imaging of TAF3 in myotubes. (Panel i) TAF3-mEos2 (green) and LaminA-PSCFP2 (red). Panels ii and iii are the enlarged images of two subsections from panel i. nu labels the intranuclear region. (Panel iv) Counting molecules at the nuclear periphery of the two nuclei shown in $A$. Bars: $A, 2 \mu \mathrm{m} ; C, D, 500 \mathrm{~nm}$. molecules at the nuclear periphery than the nuclear interior (Fig. 6D). The fact that increased TAF3 occupancy at the $M y o D$ promoter accompanies the loss of spatial segregation between TAF3 and the MyoD gene in myotubes phenocopies the observation in myoblasts when we generated a $M y o D$ promoter transgene that localizes largely to the nuclear interior and detected a higher TAF3 occupancy at this transgene promoter than the native $M y o D$ promoter (Fig. 4D). At this point, we have not determined what mediates this loss of spatial segregation between TAF3 and the $M y o D$ gene after differentiation. It is possible that the strong enrichment of heterochromatin at the nuclear periphery and the limited amount of Pol II/TAF3 factors in terminally differentiated myotubes could account for the restriction of both active genes and core transcription factors to the nuclear interior.

\section{Discussion}

Our studies were specifically aimed at tracking components of the core promoter regulatory factors and were instigated by the recent evidence that multisubunit transcription cofactors may play unexpectedly important regulatory roles during differentiation and development (for reviews, see D'Alessio et al. 2009; Goodrich and Tjian 2010; Muller et al. 2010). Although much has been gleaned regarding the regulatory functions of transcription cofactor complexes employing a combination of in vitro biochemical assays, in vivo RNAi functional assays, and structural analyses (Zhai et al. 2005; Marr et al. 2006; Liu et al. 2009), investigations have only recently been turned to how these key basal factors target specific genes in living cells (Giglia-Mari et al. 2009; de Graaf et al. 2010). Here, we observed the differential subnuclear distributions of general transcription factors TFIID and TAF3 relative to the nuclear periphery, which is correlated with selective core promoter factor occupancy at the promoter of $M y o D$, the master regulator of myogenesis. Ectopically altering the location of $M y o D$ promoters to the nuclear interior or manipulating higher concentrations of TAF3 protein to the nuclear periphery suggests that the segregation between TAF3 and the $M y o D$ promoter in myoblasts is functionally linked to the selective occupancy of TAF3 at the endogenous $M y o D$ promoter. Intriguingly, we observed that, after differentiation into myotubes, the $M y o D$ locus repositions to the nuclear interior, where TAF3 resides. This repositioning of $M y o D$ gene is accompanied by an increased occupancy of TAF3 at MyoD promoters. Using 
live-cell imaging in Caenorhabditis elegans, tissue-specific promoters were found to reposition during differentiation, and ectopically expressing HLH-1 (an MyoD homolog) can induce the inward relocation of muscle promoters (Meister et al. 2010). This and our work suggest potentially important roles of transcription factors during differentiation-induced nuclear reorganization.

Our findings underscore the possibility that local compartmentalized availability of transcription factors in the nucleus may be an important yet not fully appreciated mechanism governing gene regulation. Although in vitro biochemical analyses have established various specific transcription reactions that can occur when multiple minimally required components are reconstituted in test tubes, it has become clear that only a subset of such reactions might take place in vivo partly due to differential local site availabilities of promoter recognition factors. In the cell nucleus, how transcription factors find their target genes is a difficult and interesting problem. Cooperative interactions with cofactors or the chromatin landscape may determine the binding of certain sequencespecific transcription factors to their cognate DNA elements (Joshi et al. 2007; Guertin and Lis 2010). Our studies underscore another aspect for this problem in that the sequestration of core promoter factors such as TAF3 (which does not directly bind DNA) from the nuclear periphery may be functionally important for their selective access to target promoters. Conversely, some regulatory factors were found to be sequestered and enriched at the nuclear periphery (Lee et al. 2006; Heessen and Fornerod 2007), and the association of Oct-1 with Lamin $\mathrm{B} 1$ at the NL was reported to regulate the oxidative stress response (Malhas et al. 2009), suggesting that these subnuclear segregation phenomena may play unexpectedly broad roles in cellular functions. In C. elegans, emr-1 (emerin) was found to be a negative regulator of PHA-4 binding to pseudochromosomes bearing the pax-1 promoter (Fakhouri et al. 2010). It will be interesting to explore whether additional transcription factors may be found to segregate from the nuclear periphery, and to further investigate its functional implications during gene regulation, differentiation, and development.

Covalent modifications of histone tails are important epigenetic marks that can be associated with a repertoire of cognate regulatory factors (Jenuwein and Allis 2001). We found that specific recognitions of the TAF3 PHD finger domain to histone modifications may be required for the sequestration of TAF3 away from the nuclear periphery. Unlike specific DNA sequences, covalent modifications of histone tails are likely to be largely exposed on the surface of nucleosome core particles if not in association with other binding partners, and H3K4Me3 may provide such a recognition substrate for interactions with the TAF3 PHD domain. Thus, in addition to the well-documented role of TAF3-H3K4me3 that has been reported in the context of holo-TFIID (Vermeulen et al. 2007), our studies reveal potentially novel transactions between TAF3 and chromatin involving selective sequestration in subnuclear compartments. It is likely that H3K4Me3 and TAF3 are not in stoichiometric amounts in the cell. For instance, in myotubes, where TAF3 is largely restricted to the nuclear interior and heterochromatin is very pronounced at the nuclear periphery, $\mathrm{H} 3 \mathrm{~K} 4 \mathrm{Me} 3$ is still detectable in close proximity to the NL (Fig. 6C; Supplemental Fig. S4). We note that numerous other nuclear proteins reportedly bind to $\mathrm{H} 3 \mathrm{~K} 4 \mathrm{Me} 3$ and other modifications in structural proximity, and these additional factors and interactions may also be involved in further restricting TAF3 localization.

Superresolution light microscopy has the potential to significantly bridge the critical gap between in vitro reconstituted biochemistry and cell biology at the singlemolecule and single-cell level (Ji et al. 2008; Gould et al. 2009; Toomre and Bewersdorf 2010). Imaging transcription in the cell nucleus might particularly benefit from the development of this method, because many nuclear substructures and interactions fall below the resolving power of diffraction-limited light microscopy. Our high-resolution PALM localization analysis of TFIID versus TAF3 provides a new assay to dissect differential subnuclear distributions of these transcription factors. With the advent of superresolution microscopy, localizing and counting individual coactivator complexes as well as sequence-specific transcription factors ushers in a new era of "single-cell biochemistry" that will provide a powerful complement to many other approaches and assist us in deciphering the diversity of cellular mechanisms responsible for directing cell-specific programs of transcription during development.

\section{Materials and methods}

\section{FISH and immunofluorescence staining}

DNA and RNA FISH were performed as in Johnson et al. (1991). Probes were labeled with digoxigenin by nick translation (Roche). Labeled probes were purified by Qiagen PCR Purification columns, concentrated in a Speed-Vac, mixed with the hybridization mix, and denatured at $95^{\circ} \mathrm{C}$. The following antibodies were used for immunostaining: Pol II (4H8), Pol II Ser5P (ab5131), TAF11 (ab57501), TBP (ab818), H3K9Me3 (ab8898), and H3K4Me3 (ab8580). Antibodies for TAF4, TRF3, and TAF3 are laboratory stocks. See the Supplemental Material for more details.

\section{Cell culture}

Mouse $\mathrm{C} 2 \mathrm{C} 12$ cells were cultured at $37^{\circ} \mathrm{C}, 5 \% \mathrm{CO}_{2}$, with $10 \%$ FBS in DMEM (Invitrogen). To induce differentiation, myoblasts were grown to full confluency, and the culture medium was changed to $2 \%$ horse serum in DMEM. Primary myoblasts were derived from newborn mice and cultured as described previously (Hu et al. 2008). For live-cell imaging, myoblasts were transfected with Lipofectamine 2000 (Invitrogen) and visualized on 35-mm MatTek dishes with an LSM 510 confocal laser-scanning microscope (Zeiss). For immunostaining and immuno-FISH, myoblasts and myotubes were cultured in $\mathrm{CC} 2$ coated-chamber slides (Fisher) and treated as described previously.

\section{ChIP assay}

ChIP assay was performed as described (Deato and Tjian 2007), except that Magnetic Protein G beads (Invitrogen) were used for immunoprecipitation. The following antibodies were used: rabbit anti-TAF1 (Abcam), rabbit anti-TAF3 (laboratory stock), and 
rabbit anti-Flag (Sigma, F7425). For the ChIP experiments described in Figure 4, H and I, C2C12 myoblasts were grown to $1 \times$ $10^{8}$ to $2 \times 10^{8}$; transfected with GFP-Flag-TAF3, GFP-Flag-BAF, and GFP-Flag-BAF-TAF3 with Lipofectamine 2000; and fixed after $24-36 \mathrm{~h}$. The chromatin was prepared and immunoprecipitated using the anti-Flag antibody. The transfection efficiencies were estimated to be $\sim 10 \%-20 \%$ in all cases by checking GFP expression. qPCR was performed with an MX3005P (Stratagene) system using Brilliant II SYBR Green qPCR Master Mix (Strategene). Primer sequences are available on request.

\section{Sample processing for PALM}

C2C12 myoblast cells were grown as a monolayer on 3-mm sapphire disks (TechoTrade International, Inc.), transfected with plasmids with Lipofectamine 2000, and high-pressure-frozen the following day using a Wohlwend HPF Compact 01 (Wohlwend Engineering $\mathrm{GmBH}$ ). C2C12 myotube cells were collected and transfected using the Amaxa Nucleofection system (Lonza), and were plated on 3-mm sapphire disks and cultured overnight before HPF. The frozen cells were freeze-substituted with $1 \%$ glutaraldehyde and $0.5 \%$ uranyl acetate in $95 \%$ ethanol. Following freeze substitution, the cells were infiltrated with LR White resin (Hard grade; London Resin Co.), and polymerized overnight at $-20^{\circ} \mathrm{C}$ using the LR White cold accelerator (Brown et al. 2010). After polymerization, the sapphire disk was removed from sample blocks before sectioning, and 100-nm sections were cut with a Leica UC6 ultramicrotome (Leica Microsystems). The sections were picked up on 25-mm glass coverslips (Warner Instruments) and stored at $4^{\circ} \mathrm{C}$ in the dark until imaged.

\section{PALM imaging and analysis}

Dual-color PALM imaging and analysis were performed as described in Shroff et al. (2007). Briefly, the coverslips were mounted in an imaging chamber and covered with PBS, and fiducial beads (http://www.microsphere-nanosphere.com) were added to the sections. Cells were located by illumination with a 488-nm laser at low intensities. Then, red mEos2 fluorescence was photoactivated with a 405-nm laser and imaged with a 561-nm laser at $20 \mathrm{~Hz}$ until mEos2 underwent complete photo-conversion. Detection was then switched to the green channel, PSCFP2 molecules were photo-bleached, and the remaining inactive PSCFP2 molecules were photo-activated with a 405-nm laser. A custom-written Matlab script was used to generate molecule-counting histograms.

\section{Acknowledgments}

We thank G. Rubin, R. Singer, and The Janelia Farm Single Cell Biochemistry Consortium for the insights; H. Shroff for help on PALM imaging; Y. Li and D. Koulechova for cloning some of the DNA constructs; W.-P. Li and H. White for experimental help; and J. Lim for editorial assistance. We thank H. Timmers, B. Glick, G. Paterson, L. Looger, R. Kumaran, J. Qiao, and Z. Liu for sharing reagents, and S. Gasser, J. Lis, T. Misteli, D. Spector, and the Tjian Laboratory for critical reading of this manuscript. R.T. is an investigator of the Howard Hughes Medical Institute and Director of the Li Ka-Shing Center for Biomedical and Health Sciences.

\section{References}

Akhtar A, Gasser SM. 2007. The nuclear envelope and transcriptional control. Nat Rev Genet 8: 507-517.

Andrulis ED, Neiman AM, Zappulla DC, Sternglanz R. 1998. Perinuclear localization of chromatin facilitates transcriptional silencing. Nature 394: 592-595.
Bancaud A, Huet S, Daigle N, Mozziconacci J, Beaudouin J, Ellenberg J. 2009. Molecular crowding affects diffusion and binding of nuclear proteins in heterochromatin and reveals the fractal organization of chromatin. EMBO I 28: 3785-3798.

Bates M, Huang B, Dempsey GT, Zhuang X. 2007. Multicolor super-resolution imaging with photo-switchable fluorescent probes. Science 317: 1749-1753.

Betzig E, Patterson GH, Sougrat R, Lindwasser OW, Olenych S, Bonifacino JS, Davidson MW, Lippincott-Schwartz J, Hess HF. 2006. Imaging intracellular fluorescent proteins at nanometer resolution. Science 313: 1642-1645.

Brown TA, Fetter RD, Tkachuk AN, Clayton DA. 2010. Approaches toward super-resolution fluorescence imaging of mitochondrial proteins using PALM. Methods 51: 458-463.

Chuang $\mathrm{CH}$, Carpenter AE, Fuchsova B, Johnson T, de Lanerolle P, Belmont AS. 2006. Long-range directional movement of an interphase chromosome site. Curr Biol 16: 825-831.

Cremer T, Cremer C. 2001. Chromosome territories, nuclear architecture and gene regulation in mammalian cells. Nat Rev Genet 2: 292-301.

D'Alessio JA, Wright KJ, Tjian R. 2009. Shifting players and paradigms in cell-specific transcription. Mol Cell 36: 924-931.

Darzacq X, Yao J, Larson DR, Causse SZ, Bosanac L, de Turris V, Ruda VM, Lionnet T, Zenklusen D, Guglielmi B, et al. 2009. Imaging transcription in living cells. Annu Rev Biophys 38: 173-196.

Davies HG. 1967. Fine structure of heterochromatin in certain cell nuclei. Nature 214: 208-210.

Deato MD, Tjian R. 2007. Switching of the core transcription machinery during myogenesis. Genes Dev 21: 2137-2149.

Deato MD, Marr MT, Sottero T, Inouye C, Hu P, Tjian R. 2008. MyoD targets TAF3/TRF3 to activate myogenin transcription. Mol Cell 32: 96-105.

de Graaf P, Mousson F, Geverts B, Scheer E, Tora L, Houtsmuller AB, Timmers HT. 2010. Chromatin interaction of TATAbinding protein is dynamically regulated in human cells. J Cell Sci 123: 2663-2671.

Edmondson DG, Olson EN. 1989. A gene with homology to the myc similarity region of MyoD1 is expressed during myogenesis and is sufficient to activate the muscle differentiation program. Genes Dev 3: 628-640.

Fakhouri TH, Stevenson J, Chisholm AD, Mango SE. 2010. Dynamic chromatin organization during foregut development mediated by the organ selector gene PHA-4/FoxA. PLoS Genet 6: e1001060. doi: 10.1371/journal.pgen.1001060.

Farnham PJ. 2009. Insights from genomic profiling of transcription factors. Nat Rev Genet 10: 605-616.

Finlan LE, Sproul D, Thomson I, Boyle S, Kerr E, Perry P, Ylstra B, Chubb JR, Bickmore WA. 2008. Recruitment to the nuclear periphery can alter expression of genes in human cells. PLoS Genet 4: e1000039. doi: 10.1371/journal.pgen. 1000039.

Gangloff YG, Pointud JC, Thuault S, Carre L, Romier C, Muratoglu S, Brand M, Tora L, Couderc JL, Davidson I. 2001. The TFIID components human TAF(II)140 and Drosophila BIP2 (TAF(II)155) are novel metazoan homologues of yeast TAF(II)47 containing a histone fold and a PHD finger. Mol Cell Biol 21: 5109-5121.

Giglia-Mari G, Theil AF, Mari PO, Mourgues S, Nonnekens J, Andrieux LO, de Wit J, Miquel C, Wijgers N, Maas A, et al. 2009. Differentiation driven changes in the dynamic organization of Basal transcription initiation. PLOS Biol 7: e1000220. doi: 10.1371 /journal.pbio.1000220.

Goodrich JA, Tjian R. 2010. Unexpected roles for core promoter recognition factors in cell-type-specific transcription and gene regulation. Nat Rev Genet 11: 549-558. 
Gould TJ, Verkhusha VV, Hess ST. 2009. Imaging biological structures with fluorescence photoactivation localization microscopy. Nat Protoc 4: 291-308.

Guertin MJ, Lis JT. 2010. Chromatin landscape dictates HSF binding to target DNA elements. PLoS Genet 6: e1001114. doi: 10.1371/journal.pgen.1001114.

Hager GL, McNally JG, Misteli T. 2009. Transcription dynamics. Mol Cell 35: 741-753.

Heessen S, Fornerod M. 2007. The inner nuclear envelope as a transcription factor resting place. EMBO Rep 8: 914-919.

Hu P, Geles KG, Paik JH, DePinho RA, Tjian R. 2008. Codependent activators direct myoblast-specific MyoD transcription. Dev Cell 15: 534-546.

Iwase S, Lan F, Bayliss P, de la Torre-Ubieta L, Huarte M, Qi HH, Whetstine JR, Bonni A, Roberts TM, Shi Y. 2007. The X-linked mental retardation gene SMCX/JARID1C defines a family of histone H3 lysine 4 demethylases. Cell 128: 1077-1088.

Jenuwein T, Allis CD. 2001. Translating the histone code. Science 293: 1074-1080.

Ji N, Shroff H, Zhong H, Betzig E. 2008. Advances in the speed and resolution of light microscopy. Curr Opin Neurobiol 18: 605-616.

Johnson CV, Singer RH, Lawrence JB. 1991. Fluorescent detection of nuclear RNA and DNA: implications for genome organization. Methods Cell Biol 35: 73-99.

Joshi R, Passner JM, Rohs R, Jain R, Sosinsky A, Crickmore MA, Jacob V, Aggarwal AK, Honig B, Mann RS. 2007. Functional specificity of a Hox protein mediated by the recognition of minor groove structure. Cell 131: 530-543.

Kumaran RI, Spector DL. 2008. A genetic locus targeted to the nuclear periphery in living cells maintains its transcriptional competence. J Cell Biol 180: 51-65.

Kumaran RI, Thakar R, Spector DL. 2008. Chromatin dynamics and gene positioning. Cell 132: 929-934.

Lan F, Collins RE, De Cegli R, Alpatov R, Horton JR, Shi X, Gozani O, Cheng X, Shi Y. 2007. Recognition of unmethylated histone H3 lysine 4 links BHC80 to LSD1-mediated gene repression. Nature 448: 718-722.

Lee H, Quinn JC, Prasanth KV, Swiss VA, Economides KD, Camacho MM, Spector DL, Abate-Shen C. 2006. PIAS1 confers DNA-binding specificity on the Msx1 homeoprotein. Genes Dev 20: 784-794.

Liu WL, Coleman RA, Grob P, King DS, Florens L, Washburn MP, Geles KG, Yang JL, Ramey V, Nogales E, et al. 2008. Structural changes in TAF4b-TFIID correlate with promoter selectivity. Mol Cell 29: 81-91.

Liu WL, Coleman RA, Ma E, Grob P, Yang JL, Zhang Y, Dailey G, Nogales E, Tjian R. 2009. Structures of three distinct activator-TFIID complexes. Genes Dev 23: 1510-1521.

Lusk CP, Blobel G, King MC. 2007. Highway to the inner nuclear membrane: rules for the road. Nat Rev Mol Cell Biol 8: 414-420.

Malhas AN, Lee CF, Vaux DJ. 2009. Lamin B1 controls oxidative stress responses via Oct-1. J Cell Biol 184: 45-55.

Marr MT II, Isogai Y, Wright KJ, Tjian R. 2006. Coactivator cross-talk specifies transcriptional output. Genes Dev 20: $1458-1469$.

Meister P, Towbin BD, Pike BL, Ponti A, Gasser SM. 2010. The spatial dynamics of tissue-specific promoters during $C$. elegans development. Genes Dev 24: 766-782.

Misteli T. 2007. Beyond the sequence: cellular organization of genome function. Cell 128: 787-800.

Moen PT Jr, Johnson CV, Byron M, Shopland LS, de la Serna IL, Imbalzano AN, Lawrence JB. 2004. Repositioning of musclespecific genes relative to the periphery of SC-35 domains during skeletal myogenesis. Mol Biol Cell 15: 197-206.
Muller F, Zaucker A, Tora L. 2010. Developmental regulation of transcription initiation: more than just changing the actors. Curr Opin Genet Dev 20: 533-540.

Naar AM, Lemon BD, Tjian R. 2001. Transcriptional coactivator complexes. Annu Rev Biochem 70: 475-501.

Peric-Hupkes D, Meuleman W, Pagie L, Bruggeman SW, Solovei I, Brugman W, Graf S, Flicek P, Kerkhoven RM, van Lohuizen M, et al. 2010. Molecular maps of the reorganization of genome-nuclear lamina interactions during differentiation. Mol Cell 38: 603-613.

Reddy KL, Zullo JM, Bertolino E, Singh H. 2008. Transcriptional repression mediated by repositioning of genes to the nuclear lamina. Nature 452: 243-247.

Schermelleh L, Carlton PM, Haase S, Shao L, Winoto L, Kner P, Burke B, Cardoso MC, Agard DA, Gustafsson MG, et al. 2008. Subdiffraction multicolor imaging of the nuclear periphery with $3 \mathrm{D}$ structured illumination microscopy. Science 320: 1332-1336.

Schmid M, Arib G, Laemmli C, Nishikawa J, Durussel T, Laemmli UK. 2006. Nup-PI: the nucleopore-promoter interaction of genes in yeast. Mol Cell 21: 379-391.

Segura-Totten M, Wilson KL. 2004. BAF: roles in chromatin, nuclear structure and retrovirus integration. Trends Cell Biol 14: 261-266.

Shimi T, Pfleghaar K, Kojima S, Pack CG, Solovei I, Goldman AE, Adam SA, Shumaker DK, Kinjo M, Cremer T, et al. 2008. The A- and B-type nuclear lamin networks: microdomains involved in chromatin organization and transcription. Genes Dev 22: 3409-3421.

Shroff H, Galbraith CG, Galbraith JA, White H, Gillette J, Olenych S, Davidson MW, Betzig E. 2007. Dual-color superresolution imaging of genetically expressed probes within individual adhesion complexes. Proc Natl Acad Sci 104: 20308-20313.

Sinclair P, Bian Q, Plutz M, Heard E, Belmont AS. 2010. Dynamic plasticity of large-scale chromatin structure revealed by selfassembly of engineered chromosome regions. J Cell Biol 190: 761-776.

Spector DL. 2003. The dynamics of chromosome organization and gene regulation. Annu Rev Biochem 72: 573-608.

Tapscott SJ, Davis RL, Thayer MJ, Cheng PF, Weintraub H, Lassar AB. 1988. MyoD1: a nuclear phosphoprotein requiring a Myc homology region to convert fibroblasts to myoblasts. Science 242: 405-411.

Toomre D, Bewersdorf J. 2010. A new wave of cellular imaging. Annu Rev Cell Dev Biol 26: 285-314.

van Ingen $\mathrm{H}$, van Schaik FM, Wienk $\mathrm{H}$, Ballering J, Rehmann $\mathrm{H}$, Dechesne AC, Kruijzer JA, Liskamp RM, Timmers HT, Boelens R. 2008. Structural insight into the recognition of the H3K4me3 mark by the TFIID subunit TAF3. Structure 16: $1245-1256$.

Vermeulen M, Mulder KW, Denissov S, Pijnappel WW, van Schaik FM, Varier RA, Baltissen MP, Stunnenberg HG, Mann M, Timmers HT. 2007. Selective anchoring of TFIID to nucleosomes by trimethylation of histone H3 lysine 4. Cell 131: 58-69.

Wright KJ, Marr MT II, Tjian R. 2006. TAF4 nucleates a core subcomplex of TFIID and mediates activated transcription from a TATA-less promoter. Proc Natl Acad Sci 103: 1234712352.

Yao J, Ardehali MB, Fecko CJ, Webb WW, Lis JT. 2007. Intranuclear distribution and local dynamics of RNA polymerase II during transcription activation. Mol Cell 28: 978-990.

Zhai W, Jeong H, Cui L, Krainc D, Tjian R. 2005. In vitro analysis of huntingtin-mediated transcriptional repression reveals multiple transcription factor targets. Cell 123: 1241-1253. 


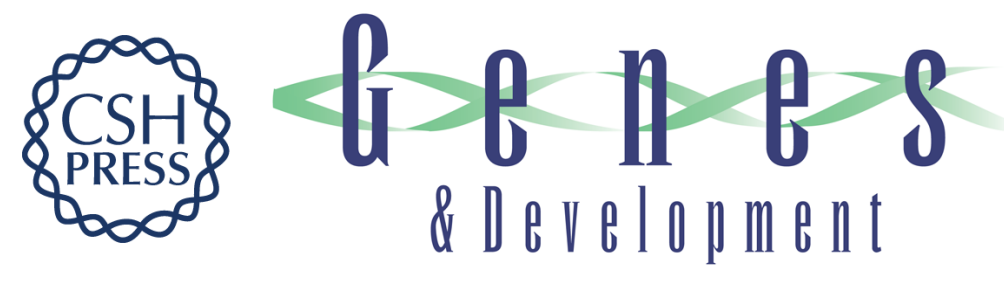

\title{
Subnuclear segregation of genes and core promoter factors in myogenesis
}

\author{
Jie Yao, Richard D. Fetter, Ping Hu, et al.
}

Genes Dev. 2011, 25: originally published online February 28, 2011

Access the most recent version at doi:10.1101/gad.2021411

\section{Supplemental http://genesdev.cshlp.org/content/suppl/2011/02/28/gad.2021411.DC1 Material}

References This article cites 61 articles, 20 of which can be accessed free at: http://genesdev.cshlp.org/content/25/6/569.full.html\#ref-list-1

License Freely available online through the Genes \& Development Open Access option.
Email Alerting Receive free email alerts when new articles cite this article - sign up in the box at the top Service right corner of the article or click here.

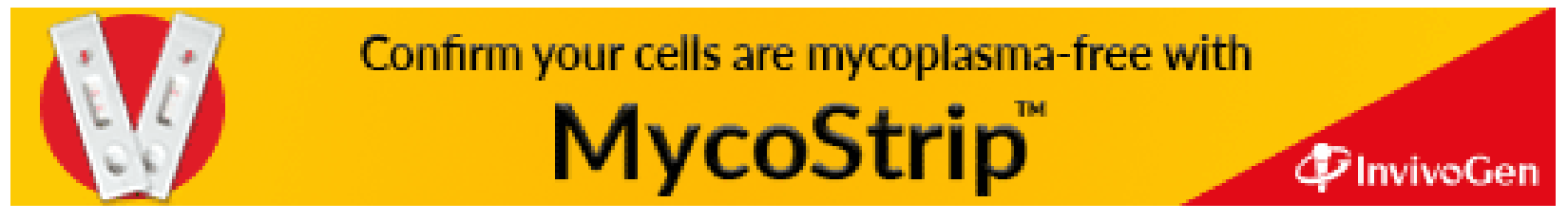

